\title{
EL MUSEO PEDAGÓGICO DE OTONES. UNA EXPERIENCIA RURAL EN LA DIFUSIÓN DEL PATRIMONIO EDUCATIVO
}

\section{The Pedagogical Museum of Otones. A rural experience in the diffusion of the educational heritage}

Juan Francisco Cerezo Manrique

Universidad de Salamanca

Correo-e: jfcm@usal.es

Miguel Ángel Cerezo Manrique

Universidad de Valladolid

Correo-e: miguelangel.cerezo@pdg.uva.es

Recepción: I5 de enero de 2016

Envío a informantes: 2I de enero de 2016

Aceptación definitiva: 2 de marzo de 2016

Resumen: El proyecto del Museo Pedagógico de Otones ha de ubicarse en el contexto de las iniciativas que, a finales del siglo xx, van apareciendo por buena parte de la geografía española en orden a la recuperación y difusión del patrimonio educativo. Esta propuesta, gestada y desarrollada en el conjunto de actuaciones que la Asociación Cultural El Corralón de dicha localidad viene impulsando desde el comienzo de la etapa democrática, pretende constituirse, aunque modestamente, en una contribución a tal empresa, particularmente, en su dimensión rural.

Se trata, también, de un tarea colectiva que, además, proporciona espacios de participación y de creación cultural, imprescindibles en cualquier proyecto de desarrollo rural. Durante sus ya 20 años de trayectoria histórica (1996-2016) se ha caracterizado, principalmente, por poner al servicio de los ciudadanos un lugar de encuentro y de diálogo, en el que desde el material recuperado y la reconstrucción de la memoria educativa se facilitan procesos de mejora de la calidad de vida.

Por otra parte, los Museos de Otones, y, especialmente, el Pedagógico, se han convertido en un elemento dinamizador fundamental, desde la cultura y la educación, de esta pequeña población.

Palabras clave: patrimonio educativo; museos pedagógicos; etnografía escolar; historia material de la escuela; historia de la educación; desarrollo rural. 
AвsTRACT: The project of the Otones Educational Museum must be placed in the framework of the creativity of the late twentieth century which appear throughout Spain in order to recover and spread educational heritage. This proposal, created and developed in a series of activities by the Asociation town of El Corralón and its Cultural Association, which have been promoting Education since the beginning of the democratic era, is intended as a modest contribution, particularly in its rural dimension.

It also is a collective task that provides opportunities for participation and cultural creation for any essential rural development project. During its 20 years of history (1996-2016) it has been regarded as a place for citizens for meeting and dialogue, where recovered information and restoration of educational memory facilitate processes for improving the quality of life.

Moreover, the Otones Museums, and particularly the Educational museum, have become a key dynamic element of culture and education in this small town.

KEY WORDS: educational heritage; teaching museum; etnography school; education history; school history material; rural development.

\section{Introducción}

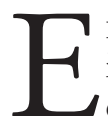
l Museo Pedagógico La Última Escuela de Otones de Benjumea es una iniciativa para la recuperación y difusión del patrimonio educativo rural, gestada y desarrollada en el seno de la Asociación Cultural El Corralón. Para que se pueda apreciar en toda su extensión la naturaleza de este proyecto museístico, presentamos, a continuación, el perfil de dicha institución, de una ya larga trayectoria, pues en el presente ejercicio cumple 40 años en la prestación de servicios socioculturales y educativos en el medio rural.

En efecto, esta Asociación, creada en 1976 , ha tenido y tiene como finalidad principal promover la cultura entendiéndola como un ámbito de desarrollo personal y colectivo. En la actualidad, cuenta con 389 socios, de los cuales algo menos de una sexta parte reside en Otones. Los demás, originarios en su mayoría de esta localidad, regresan periódicamente, sobre todo en época de vacaciones y fines de semana, y cada vez con mayor asiduidad. Entre las múltiples actividades llevadas a cabo ${ }^{\mathrm{I}}$ (animación a la lectura, teatro, danzas y música regionales, juegos y deportes autóctonos, arquitectura popular, actuaciones en el medio ambiente, etc.), interesa destacar ahora las que desde hace ya dos décadas se vienen emprendiendo para rescatar y poner en valor el patrimonio cultural propio. En este contexto, la junta directiva de la Asociación, al elaborar la programación para el ejercicio de 1995-96, acordó que uno de los ámbitos en los que se precisaba profundizar era el relacionado con la recuperación de la historia y de las tradiciones de las que éramos protagonistas, nosotros o nuestros antepasados. Y ello por entender que desde esta perspectiva, a la vez que se conseguía la preservación de la memoria colectiva y de las señas de identidad, se facilitaban procesos de participación y de creación cultural, imprescindibles en cualquier proyecto de desarrollo y de mejora de la calidad de vida. En consecuencia, la A. C. El Corralón, además de otros proyectos orientados hacia este objetivo, ha promovido la creación

Todo este conjunto de actividades desarrolladas por la A. C. El Corralón durante sus 40 años de existencia pueden consultarse en sus libros de actas, en sus memorias y en otra documentación complementaria elaborada al efecto. 
de dos iniciativas museísticas, el Museo Etnográfico de Otones de Benjumea², en el que se recopilan y exhiben los objetos propios de la vida cotidiana en sus más diversas manifestaciones, y el Museo Pedagógico que recoge y muestra el pasado escolar de este pequeño pueblo castellanoleonés.

Como venimos diciendo, el proyecto colectivo que aquí se presenta tiene como objetivo central recuperar el patrimonio histórico educativo, ponerlo en valor y a disposición de la comunidad científica y de la ciudadanía, en general, para su conservación, estudio y disfrute. Pretende constituirse, así, aunque modestamente, en una contribución, particularmente en su dimensión rural, a la empresa común, iniciada hace varias décadas y extendida ya por toda la geografía española en forma de museos de la educación de variada tipología. Pero con la finalidad compartida de reconstruir la memoria pedagógica, impulsar la investigación en historia de la educación y, sobre todo, poner al servicio de la sociedad el patrimonio recuperado. A este respecto, pueden consultarse, entre otros, los siguientes trabajos que dan cumplida cuenta de este proceso (Martínez, 1993; Ruiz Berrio, 2000, 2006; Hernández Díaz, 2000, 2003; Cerezo y Cerezo, 200I; Peña, 200I, 2006; Jiménez, 2003; Terrón, 2003; Escolano, 2006, 2007; Álvarez Domínguez, 20Io; Carrillo y Collelldemont, 2007; Gónzalez Ruiz, 2007; Juan, 2007; Martín, 2007, 2008; Peralta, 2009; Castro, 20ıo; Reyes, 20I2; Dávila y Naya, 20I4).

El Museo se encuentra ubicado en el edificio que albergó las escuelas de niños y de niñas de Otones ${ }^{3}$ entre 1961 y 1971. La primera fecha es la de su apertura, perteneciente al plan de construcciones escolares de 1956. La segunda es la de su cierre e integración en la Escuela Comarcal de Turégano. La propuesta de concentraciones escolares como modelo organizativo de la escuela rural, impulsada por la Ley General de Educación de 1970, dejaba sentir sus efectos negativos para aquellos pueblos que, como el nuestro, perdían su principal foco de educación y cultura. Como consecuencia, se sometía a estos núcleos de población y a sus familias a un proceso de separación y desintegración que, progresivamente, devendría en su progresivo despoblamiento4 ${ }^{4}$

\section{Orígenes y desarrollo histórico del Museo Pedagógico de Otones}

Los orígenes del Museo obedecen a dos tipos de factores. Por una parte, como ya se ha indicado, están los que tienen que ver con las actividades de la propia Asociación

\footnotetext{
El Museo Etnográfico de Otones, creado también en 1996, guarda y presenta para su estudio y contemplación un amplísimo muestrario de objetos antiguos, más de 5.000 , pertenecientes a un periodo de tiempo comprendido entre mediados del siglo xIx y los años 70 del siglo Xx. A través de estos materiales se puede reconstruir la vida cotidiana de los habitantes del medio rural. Las labores agrícolas y ganaderas; otros oficios que complementaban las principales actividades productivas; los útiles del hogar; el ajuar de la casa; los juegos, deportes tradicionales y otras formas de esparcimiento; colecciones de fotos antiguas, noticias de prensa sobre nuestro pueblo y muestras de la publicidad de la época; información sobre costumbres y tradiciones propias, todo ello está representado en las distintas dependencias del Museo.

3 La dirección postal del Museo es calle de las Escuelas, s/n. CP 40394. Otones de Benjumea (Segovia). Teléfonos 92I 4347 50; 921 50 I0 38; 92150 Io 17; 686 o68 04I. En cuanto a la página web, cuentas de correo electrónico y redes sociales se está diseñando un proyecto para adaptarlas específicamente al Museo. Mientras tanto, se están utilizando las siguientes: asociacioncultural.elcorralón@hotmail.com y jfcm@usal. es; wwrw.otones.net; https://www.facebook.com/Otones-de-Benjumea-285317974863149/ https://www.facebook.com/acelcorralon/ www.otones.net.

4 En la década que va de 1970 a 1980 Otones pierde casi un $25 \%$ de su población pasando de 205 a 160 habitantes.
} 
Cultural. Y, por otra, los que se derivan de la influencia ejercida por la tendencia historiográfica, emergente en la última década del pasado siglo, que pone el énfasis en lo que en esos momentos se comenzó a llamar, entre otras denominaciones, la historia material de la educación. Disponemos ya de un buen número de trabajos que nos advierten de la consolidación de esta nueva propuesta (Hernández, 1993, 1997, 2002; Escolano 2000, 2002, 2007; Ruiz Berrio, 2000, 2002, 2010; López, 2001; Escolano y Hernández, 2002; Viñao, 2002, 2005; Álvarez Domínguez, 2007, 2010; AA. vv., 2008; Somoza y Yanes, 2009; Ossenbach, 20Io; Depaepe y Simon, 20I4; Sanchidrián, 20I4).

En cuanto a los primeros, hemos de recordar que en 1996 la Asociación se propone recuperar la historia de la escuela de Otones, acordando la realización de una exposición temporal que llevaría por título La Última Escuela. Calificativo que se ajustaba a la realidad, puesto que la escuela se había cerrado en i97i, y servía, a la vez, como denuncia testimonial de la controvertida medida. Con la iniciativa se pretendía también rendir un homenaje a los maestros y maestras, a los niños y niñas que alentaron el discurrir de la escuela, de tan decisiva importancia en la vida de todos.

Esta decisión, por otra parte, surge y se consolida en el contexto de las iniciativas que se están emprendiendo por toda la geografía española y que empiezan a configurar una nueva forma de hacer Historia de la Educación. Algunas de estas realizaciones se concretan en proyectos de investigación e iniciativas editoriales como el proyecto interuniversitario MANES. 1992 (Ossenbach, 2007) o la publicación de la Fundación Germán Sánchez Ruipérez La bistoria ilustrada del libro escolar y de la escuela en España (Escolano, 1997, 1998, 2006). Asimismo, se organizan exposiciones histórico-escolares de carácter local, regional o nacional. Tuvieron una gran resonancia y acogida la de La escuela del ayer en Cantabria (Fundación Santillana) (1988); Cien años de escuela en España (I875-1975), Diputación de Salamanca (1990); la exposición de ANele, El libro y la escuela, en la Biblioteca Nacional (I992); la exposición itinerante de sTES de Castilla y León La escuela del ayer (1993); la exposición Recuerdos de un olvido. Los libros en que aprendimos, de Javier Cabornero, Valladolid (1997), o la exposición 70 años de escuela pública, Ceip Primo de Rivera de Segovia (1998), por nombrar algunas de las locales. Renace, finalmente, el interés por los museos pedagógicos. Los primeros que se crean en estos años son El Museo del niño de Albacete (1987), El Museo pedagógico de Huesca (1990) y El Museo de Historia de la Educación de la Facultad de Educación de la UCM (1992).

Explicitado el contexto en el que se inscribe La Última Escuela de Otones, pasamos a completar la narración de su momento fundacional. El proyecto, que conllevó un laborioso trabajo de acondicionamiento del edificio escolar, pues había permanecido cerrado durante un cuarto de siglo; de búsqueda de materiales, libros, mobiliario, etc., y de investigación sobre su funcionamiento, pudo hacerse, finalmente, realidad gracias a la colaboración de un gran número de socios. En consecuencia, en el verano de 1996 se inauguraba la exposición La Última Escuela de Otones de Benjumea, que recuperaba la historia de una pequeña escuela rural desde principios del siglo xx hasta el momento de su cierre, en 1971. En ella se podían encontrar referencias de los maestros que enseñaron, los libros de texto y de lectura con los que se aprendía, los cuadernos de las tareas y los deberes, los recursos didácticos que posibilitaban y hacían más ameno el aprendizaje, los juegos y juguetes, el mobiliario que se utilizó... En suma, la exposición mostraba un conjunto de objetos a través de los que los visitantes podían reconstruir un pasado escolar común a varias generaciones que convivieron 
EL MUSEO PEDAGÓGICO DE OTONES. UNA EXPERIENCIA RURAL

EN LA DIFUSIÓN DEL PATRIMONIO EDUCATIVO

JUAN FRANCISCO CEREZO MANRIQUE Y MIGUEL ÁNGEL CEREZO MANRIQUE

en el mismo escenario de referencia, como fue Otones. A la vez, se ofrecían nuevas posibilidades de estudio de la educación en perspectiva histórica a través de los objetos escolares.

La aceptación y el éxito de la exposición fueron notables. No solo los originarios del lugar quedaron impresionados con la muestra, sino que la afluencia de visitantes de otros lugares superó todas las previsiones. A ello, sin duda, contribuyeron los medios de comunicación provinciales al hacerse eco del acontecimiento educativo. Circunstancias estas que iban a influir en que la muestra no se clausurase en las fechas previstas y en que se mantuviese indefinidamente. Esta decisión, sugerida por no pocos visitantes y, finalmente, adoptada por la junta directiva de la Asociación, se mostraría a la postre como muy acertada. En efecto, en los primeros años de andadura el número de personas que, bien a título individual o formando parte de diversas instituciones, se desplazaron hasta Otones para ver y estudiar la exposición sobre su escuela fue muy considerable. Es de destacar, en este sentido, la cursada por un grupo de profesores universitarios en 1996, algunos miembros de la junta directiva de la SEDHE, que sugieren algunos cambios y mejoras como la de convertir la exposición en museo pedagógico, iniciar la catalogación de sus fondos, utilizar estos para la investigación histórico-educativa, ofrecer la posibilidad de realizar prácticas de campo, elaborar folletos informativos, guías didácticas y otras publicaciones para facilitar una mejor comprensión de la realidad expuesta en el Museo. También es de reseñar, por la repercusión que llegó a tener, la visita de la compañía de teatro Tantaka en 1997. Este grupo mantuvo en escena por toda la geografía española, durante varias temporadas, la obra El florido pensil. Este mismo año un nutrido grupo de profesores asistentes al Congreso Internacional Formación y medios, organizado por la Universidad de Valladolid, también acuden hasta Otones para ver su exposición. Ya en 1998 se va a producir otro acontecimiento decisivo en la consolidación de esta iniciativa museística, cuyos orígenes estamos contando. Nos referimos a la celebración en Otones de la primera reunión institucional de la Sociedad Castellanoleonesa de Historia de la Educación. Durante los actos celebrados en esta jornada se da a conocer el acuerdo de la creación del Museo Pedagógico de Otones a partir de la referida exposición. Los medios de comunicación provinciales y regionales darán cobertura a estas noticias, lo que va a suponer una gran difusión entre los sectores educativos de Castilla y León.

Igualmente, se recibieron y se atendieron las primeras solicitudes de préstamo de los materiales para su traslado a otros lugares con motivo de distintas conmemoraciones. Así, en 1998, La Última Escuela viaja a Segovia para configurar el espacio expositivo de la celebración de los 70 años de Escuela Pública (CEIP Primo de Rivera de Segovia). En 1999 se colabora también con distintas instituciones interesadas en disponer de los fondos del Museo. Es el caso del Centro de Profesores y Recursos de Cuéllar (Segovia) para complementar su exposición Escuela de Maricastaña y escuela digital; o el del CEIP Eresma de Segovia para ilustrar la muestra sobre los cambios operados en la educación durante el siglo xx, tema de su semana cultural. Un año más tarde, los fondos del Museo serán de nuevo trasladados a la capital segoviana con motivo de la inauguración del ceIP Elena Fortún.

Estas primeras actuaciones son, por una parte, una prueba del interés que suscita la iniciativa de la A. C. El Corralón, ya desde sus orígenes. Y, por otra, un claro indicador de la vocación de servicio público que, también desde sus comienzos, caracteriza su perfil. 


\section{Descripción, situación actual y actividades del Museo}

Ya se ha indicado que el Museo Pedagógico de Otones es una propuesta desarrollada en el ámbito de actuación de la A. C. El Corralón. Se trata, por tanto, de una iniciativa privada, de cuya gestión se encarga una comisión de coordinación, delegada de la junta directiva de la Asociación, como recogen sus estatutos. Esta comisión está compuesta por socios voluntarios, de permanencia indefinida, y por representantes de la junta directiva, cuya renovación se produce anualmente. Su estructura es de carácter abierto y flexible, lo que permite un funcionamiento ágil, adaptado a las exigencias y necesidades de cada momento. No obstante, la permanencia de algunos socios voluntarios garantiza criterios comunes de actuación en todas aquellas tareas y funciones que lo requieren (adquisición de fondos, catalogación, atención a visitantes, búsqueda de recursos, representación, etc.).

En este sentido, se ha de subrayar el dato de que el Museo cumple en este año de 2016 dos décadas de existencia. Durante este tiempo se ha comportado como un organismo vivo que ha ido creciendo en espacio, en número de fondos incorporados, en actividades realizadas y en servicios prestados a la ciudadanía.

En sus orígenes ocupaba el aula de niños de la escuela de Otones, con una superficie de 60 metros cuadrados. Después de sucesivas ampliaciones (cerramiento de soportales y patios y habilitación del aula de niñas), dispone en la actualidad de 350 metros para dependencias interiores del Museo y roo más para jardín y zona de recreo. Conviene añadir que una parte de estas obras de acondicionamiento han sido realizadas con recursos de la propia Asociación y el resto con subvenciones obtenidas del Grupo de Acción Local Segovia-Sur (Fondos Leader).

El espacio museístico está organizado en siete salas de carácter expositivo, un despacho para trabajos de gestión e investigación, un almacén y una zona de servicios higiénicos. La distribución de los fondos en cada uno de estos espacios obedece, principalmente, a criterios cronológicos y curriculares, aunque también se han utilizado algunos de carácter estético y otros exigidos por las características del edificio.

Así, la sala de entrada al Museo contiene un conjunto de materiales escolares diverso y valioso (laminario de Calleja para la enseñanza de la religión, ábaco antiguo...) con la intención de captar la atención del visitante. Integran este conjunto una completa exposición de juegos y juguetes con la explicación de sus reglas y normas; una colección de fotografías de todas las escuelas de la provincia de Segovia; una colección de libros escolares reeditados, pertenecientes a los años centrales del siglo xx; una interesante muestra de cuadernos escolares, compuesta por más de un centenar de ejemplares; un pequeño rincón destinado a publicaciones museísticas actuales (libros, memorias, revistas, carteles y folletos informativos), y, finalmente, una amplia representación, expuesta en las paredes de este espacio, de los objetos utilizados en la escuela durante buena parte del siglo pasado.

Otra de las salas está destinada a las etapas del sistema educativo reguladas por la LGE de 1970 y la LOGSE de 1990. Además de contener los libros, recursos didácticos y mobiliario, propios de este periodo, acoge una completa exposición de los materiales utilizados en la gestión de lo que podríamos denominar el tratamiento de la diversidad.

La escuela franquista es la que está más ampliamente representada en el Museo puesto que, además de un espacio amplio en el que están expuestos sus libros más representativos y parte del mobiliario y recursos empleados, dispone de un aula que 
incorpora la inmensa mayoría de los materiales característicos de la cultura escolar del nacionalcatolicismo. Son de gran interés las colecciones de láminas de religión, de mapas y de pupitres, entre otras.

El primer tercio del siglo xx y su etapa final republicana cuentan también con su lugar específico. Aunque no tan numerosos como los objetos pertenecientes a otros periodos de nuestro sistema educativo, los que representan la escuela de la república tienen un gran poder evocador de una de las más importantes etapas de la renovación pedagógica de nuestro país.

Los fondos pertenecientes al siglo XIX, menos abundantes, pero de gran valor, están distribuidos estratégicamente para que el visitante pueda apreciarlos. Destaca la colección de mapas existente.

Se ha reservado, igualmente, un espacio para exposiciones temáticas, de carácter temporal o permanente. Actualmente son tres las que pueden contemplarse. Una referida a los recursos didácticos empleados en la enseñanza de las ciencias, en la que se exhibe desde el material de laboratorio de uso escolar hasta atlas ilustrados del cuerpo humano de principios del siglo xx. Otra, relativa a los medios audiovisuales que en las diferentes etapas históricas han facilitado los aprendizajes de los escolares: linternas mágicas, proyectores de cuerpos opacos, placas de vidrio, filminas, diapositivas, magnetófonos, tocadiscos, cintas de cine, retroproyectores, ordenadores, etc. Y una tercera sobre el material de psicodiagnóstico y orientación escolar de la segunda mitad del siglo xx. En esta exposición pueden encontrarse la mayor parte de las pruebas, tests, aparatos e instrumentos que se han utilizado para medir las capacidades de niños y niñas, y orientarles escolar y profesionalmente. Por el número de fondos, por su importancia y por el interés que ha despertado, se ha decidido mantener indefinidamente esta última exposición.

En cuanto a los materiales recuperados y guardados, podemos decir que la exposición inicial contaba con 800 objetos escolares. En el momento presente, puede estimarse que el número de fondos que alberga el Museo de Otones se sitúa en el entorno de los 20.000. De ellos, unos 15.000 son libros y otro material impreso, y el resto puede encuadrarse en la categoría de útiles escolares diversos (recursos didácticos, mobiliario, juguetes, fotografías, etc.). A este respecto, es preciso destacar el esfuerzo realizado por la A. C. en la recuperación del patrimonio pedagógico, concretado en la búsqueda e incorporación del mayor número posible de los materiales escolares del ámbito rural. Estos fondos se han adquirido mediante la compra con recursos propios, a través de las donaciones de particulares y centros educativos y por medio del intercambio con otros Museoss.

Debido a la especialización y esfuerzo que requieren, el inventario y la catalogación de un número tan importante de fondos ha sido una de las tareas que no ha podido ser atendida de forma continua. Se ha necesitado ayuda externa y no siempre se ha podido conseguir. En 20or, con motivo de la publicación del libro La última escuela, se procedió a un primer inventario ${ }^{6}$ que clasificó los objetos expuestos en las siguientes categorías: mobiliario (53), recursos didácticos (124), juguetes (34), útiles de

Inicialmente, los fondos del Museo eran originarios de la escuela de Otones y de los que fueron sus usuarios. Posteriormente, la procedencia de los mismos ha sido muy diversa, como se ha indicado. No obstante, no se aprecian diferencias significativas entre el utillaje escolar en función de su destino.

6 Este primer inventario puede consultarse en Cerezo, J. F. y Cerezo, M. Á. (200I) La última escuela de Otones de Benjumea. Segovia: Asociación para el desarrollo rural de Segovia Sur. Catalogo de exposición. 
costura (23), documentos oficiales (62), cuadernos (17) y libros (479). Posteriormente, la incorporación progresiva, y en cantidades muy considerables, de nuevos fondos imposibilitó el que desde la coordinación del Museo se pudieran seguir realizando estas actividades. Se decidió, en consecuencia, acudir a convocatorias públicas de ayudas y subvenciones con resultado diverso; denegación de las solicitudes en la mayoría de las ocasiones, falta de cualificación de los seleccionados en otra y obtención de los recursos necesarios en la última presentada. Esta se refiere a la ayuda concedida por la Junta de Castilla y León para contratar a dos bibliotecarias y documentalistas durante seis meses con la función de inventariar y catalogar los fondos de los Museos de Otones. El trabajo realizado por estas profesionales ha sido muy satisfactorio. Durante los meses de primavera y verano de 2014 han inventariado, catalogado y organizado 9.800 documentos; prácticamente, la mitad de los fondos del Museo, según sus estimaciones. A tal efecto, han creado cuatro bases de datos para agrupar y clasificar los distintos tipos existentes: inventario bibliográfico (libros), publicaciones seriadas (revistas), literatura gris (cuadernos, folletos, etc.) y documentación administrativa. Para la construcción de estas bases de datos se han tenido en cuenta las Reglas de Catalogación del Ministerio de Cultura. De esta forma, además de contar con un inventario del material bibliográfico, se dispone de una catalogación ajustada a las normas ISBD (M), al haberse cumplimentado, prácticamente, todas las áreas de la descripción bibliográfica normalizada ${ }^{7}$.

En cuanto a la restauración, conservación y salvaguarda de los fondos del $\mathrm{Mu}$ seo, se ha de reconocer que la Asociación no dispone de los recursos necesarios para afrontar con total solvencia y garantía estas tareas. No obstante, en los casos en los que el deterioro de los materiales no es muy avanzado o estos no requieren de trabajos muy especializados, voluntarios de la Asociación se encargan de su restauración. En alguna ocasión muy concreta se han contratado servicios profesionales, como fue el caso del Libro de contabilidad de la escuela de Otones de roor. También sería deseable contar con suficientes medios económicos para mantener un excelente estado de conservación de todos los objetos escolares y, particularmente, de aquellos más sensibles ya sea por su antigüedad, su composición o su valor. Pero, de momento, solo podemos garantizar la que no precisa de fuertes inversiones económicas y más bien depende de la colaboración de los socios. En este sentido hemos de indicar que todo el mobiliario no escolar (estanterías, mesas, expositores, etc.), así como el mantenimiento, la limpieza y otros trabajos de acondicionamiento de la instalación se realizan habitualmente por los miembros de la comisión de coordinación de los Museos o en días de trabajo comunitario, conocidos tradicionalmente como hacenderas.

En relación con otras actividades desarrolladas por el Museo, más directamente vinculadas con los servicios que presta a la ciudadanía, podemos indicar que en cuanto a la exposición de los fondos, además de los criterios mencionados con anterioridad, la idea central es la de mostrar y dar a conocer el mayor número posible de los objetos recuperados. De tal manera que todos los visitantes encuentren y

Una ampliación de los datos de referencia puede consultarse en el Informe sobre los trabajos que se han realizado en el Museo Pedagógico La Ultima Escuela de Otones de Benjumea (2014). Elaborado por Pilar Castelao Baladrón y Juana Navarro Luis. Documento multicopiado.

8 La hacendera es definida como un «trabajo de utilidad común al que acude todo el vecindario». La A. C. El Corralón ha recuperado esta práctica tradicional para realizar tareas de interés colectivo. En todas las que se llevan a cabo a lo largo del año, los trabajos relacionados con los Museos ocupan un lugar central. 
EL MUSEO PEDAGÓGICO DE OTONES. UNA EXPERIENCIA RURAL

EN LA DIFUSIÓN DEL PATRIMONIO EDUCATIVO

JUAN FRANCISCO CEREZO MANRIQUE Y MIGUEL ÁNGEL CEREZO MANRIQUE

puedan contemplar sus útiles escolares. Objetivo que en la mayoría de las ocasiones suele conseguirse.

Por otra parte, se han organizado diversas exposiciones temáticas, con motivo de acontecimientos determinados o con la intención de dar a conocer mejor algunos de los fondos. Normalmente, han tenido lugar fuera de las instalaciones del Museo. Han sido las siguientes: Exposición de juegos y juguetes tradicionales (2003), Exposición sobre El Quijote en la escuela (2005), Exposición sobre la escuela de la II República (2006), Exposición de fotografías sobre construcciones escolares de la provincia de Segovia (2008) y Exposición sobre materiales empleados en el psicodiagnóstico y la orientación escolar en la segunda mitad del siglo XX (2012).

Aunque en menor medida que en otros ámbitos, por lo que es una de las áreas de mejora a tener en cuenta en el futuro, el Museo Pedagógico de Otones, dependiendo de sus posibilidades, también colabora y ofrece recursos para la investigación. Además de algunos trabajos elaborados por los miembros de la comisión de coordinación, se ha recibido la visita de investigadores externos y de estudiantes en periodo de elaboración de sus tesis doctorales y trabajos fin de grado y de máster de las Universidades de Valladolid y de Salamanca. El avance experimentado en las tareas de inventario y catalogación y la habilitación de un despacho facilitarán, sin duda, estos procesos.

Uno de los aspectos a los que se ha prestado especial atención es el que tiene que ver con las tareas de difusión e interpretación del patrimonio educativo recogido. Sobre estos procesos se dispone ya de importantes trabajos que, sin duda, facilitarán esta importante función social de los museos pedagógicos (Fernández, 2003; Pastor, 2004; Gómez García, 2006; Juan, 2008; Álvarez Domínguez, 2009, 20II; Rubio, 2009; Carrillo y otros, 20II).

En el caso de la A. C. El Corralón podemos destacar las siguientes iniciativas desarrolladas: reedición del libro El caso de Otones de Benjumea. Un ejemplo de acción social, I999; publicación del catálogo-libro El Museo Pedagógico la Ultima Escuela de Otones de Benjumea, 200I y el audiovisual Imágenes para la memoria de la Última Escuela, 200I; edición de folletos divulgativos sobre los Museos de Otones (25.000 ejemplares en 5 ediciones); información permanente en las secciones de agenda de los periódicos y revistas de Segovia y en guías turísticas provinciales y regionales; presencia en Internet a través de la página web y redes sociales de la propia Asociación y de otras instituciones y empresas del sector turístico; participación en programas de divulgación del patrimonio provincial a través de códigos QR o BiDi, y elaboración propia de estos códigos para facilitar la información a los visitantes.

Esta intensa tarea de difusión ha tenido su recompensa, no solamente en el incremento del número de visitantes, como luego analizaremos, sino también en los medios de comunicación que, al hacerse eco de la misma, han amplificado sus efectos. Así, durante estos años han sido numerosos los reportajes publicados en diarios, revistas, emisoras de radio y televisiones de alcance regional y nacional (El Pais, El Mundo, El Norte de Castilla, La Gaceta Regional, El Adelantado de Segovia, Revista Escuela, Tele 5, Tele Madrid, Televisión Española, Trcyl, La Ser, Radio Nacional, La Cope, entre otros). Todos ellos son indicadores del buen nivel de difusión conseguido?.

9 En la parte final de la redacción de este trabajo tres han sido las muestras de interés de los medios de comunicación por el Museo Pedagógico. Reportaje de la cadena de televisión local de Segovia y entrevistas para el semanal Escuela y para Viajar por Segovia, publicación de carácter trimestral. 
Como consecuencia, la visibilidad alcanzada por las iniciativas museísticas de Otones ha hecho posible su colaboración en distintos proyectos audiovisuales relacionados con el conocimiento, interpretación y utilización social del patrimonio educativo. Referimos algunos de ellos: grabación de algunas escenas para la película de J. L. García Sánchez sobre María Zambrano (2004); grabación de un programa de Informe Semanal sobre educación para la convivencia, TV española (2007); grabación para un documental sobre El auxilio social franquista por una empresa de medios de comunicación inglesa (20II); y grabación de las escenas referidas a la escuela y a los juegos infantiles del documental La vida en torno a un puchero (2013) sobre el cotidiano rural en los años centrales del siglo xx.

Dicha visibilidad también ha facilitado la participación en diferentes foros y reuniones de carácter académico y científico, en los que se ha solicitado la presencia y colaboración de la Asociación para exponer sus proyectos y realizaciones, tanto desde el punto de vista museístico como sociocultural. Damos cuenta de los más significativos: Reunión fundacional de la Sociedad Castellanoleonesa de Historia de la Educación; Cursos extraordinarios sobre Turismo Rural, Etnografía y Cultura Popular (Universidad de Salamanca); I Jornadas sobre Turismo Rural (Junta de Castilla y León); Programas de innovación educativa (Dirección provincial de Educación/cRA de Turégano); Encuentro de estudiantes de Magisterio de las Universidades de Valladolid y Salamanca; Ayllón. I. ${ }^{a}$ Misión Pedagógica. 75 aniversario (Ayuntamiento de Ayllón); Máster en Turismo de Interior (Universidad de Salamanca); Curso de verano Educar en el tiempo libre. Las universidades populares y otros espacios de cultura y sociabilidad (Universidad de Salamanca); Escuela de alcaldes. La sostenibilidad en municipios pequeños. Foro Fuentes Claras (Junta de Castilla y León); Primeras Jornadas sobre patrimonio educativo. Pensar y sentir la escuela (Escuela de Magisterio de Zamora. Universidad de Salamanca); Curso de directores de centros educativos de Chile (Universidad de Salamanca); Programas de doctorado y Máster (Facultad de Educación. Universidad de Salamanca); Universidad de la Experiencia (Campus de Ávila y Segovia. Junta de Castilla y León), etc.

Otro de los servicios que el Museo viene ofreciendo desde sus orígenes, como ya se indicó al comienzo de esta crónica, es el de préstamo de sus fondos. Mediante este procedimiento, diversas instituciones, como colegios, institutos, centros de profesores, asociaciones culturales, diputaciones, ayuntamientos, etc., han tenido la oportunidad de organizar exposiciones conmemorativas de determinados acontecimientos educativos. Su procedencia ha sido muy variada, de ciudades y localidades como Valladolid, Salamanca, Ávila, Segovia, Arévalo, Cantalejo, Cuéllar, Ayllón, etc. De todas ellas, ha sido la capital de Segovia la máxima receptora de estos fondos, puesto que la mayoría de sus colegios han celebrado el aniversario de su creación recreando aulas de su momento fundacional. Destacar, igualmente, la muestra que hace dos años se organizó en el campus universitario María Zambrano y en el espacio expositivo de La Cárcel con motivo de la proyección del documental Las maestras de la República.

Muy probablemente, sea la atención al público, la atención a los visitantes, el mayor y el mejor de los servicios prestados por los Museos de Otones y, particularmente, por su Museo Pedagógico. Durante sus dos décadas de existencia más de 35.000 personas se han interesado por dicha iniciativa. En los últimos años la media de visitas registradas ha estado cercana a las 2.00o. A todos o a la mayor parte se les ha ofrecido 
EL MUSEO PEDAGÓGICO DE OTONES. UNA EXPERIENCIA RURAL

EN LA DIFUSIÓN DEL PATRIMONIO EDUCATIVO

JUAN FRANCISCO CEREZO MANRIQUE Y MIGUEL ÁNGEL CEREZO MANRIQUE

una atención especializada a través de visitas guiadas adaptadas a las características de cada uno de ellos.

Personas a título individual; asociaciones culturales, de vecinos, de jubilados; grupos turísticos de la más diversa composición y procedencia; grupos de profesores e investigadores, congresistas; alumnos universitarios, nacionales y extranjeros, estudiantes de instituto, niños y niñas de educación infantil y primaria componen el perfil de los visitantes.

Una parte significativa de estos colectivos pertenece a instituciones educativas con las que la Asociación mantiene relaciones de colaboración para facilitar la visita de sus estudiantes. Algunos centros universitarios y, sobre todo, un número muy importante de los colegios de la provincia de Segovia son visitantes asiduos a los que, además, se les ofrecen prácticas de juegos y deportes tradicionales y paseos medioambientales.

Aunque de perfil heterogéneo y de procedencia muy diversa, las distintas generaciones que se han dado cita en el Museo han encontrado motivo y oportunidad para el recuerdo y para la recuperación de la memoria histórica, o para el estudio, la investigación y el aprendizaje. También para el conocimiento e identificación con la cultura escolar rural, para poner en marcha modelos y proyectos de actuación sociocultural similares y, en fin, para la admiración y el disfrute ante este rico y desconocido, para el gran público, patrimonio etnográfico educativo.

Además del reconocimiento expresado por los visitantes, de palabra, en encuestas de satisfacción o a través de los testimonios recogidos en los libros de visitas ${ }^{\mathrm{IO}}$, es preciso destacar los premios obtenidos por la Asociación, en los que la influencia del Museo ha sido decisiva. Estos son: 2009. Premio Celtiberos de oro. A la difusión cultural en el medio rural. Ayuntamiento de Torreiglesias; 20Io. Premio Fuentes Claras. Al desarrollo sostenible en municipios menores de ı.ooo habitantes. Junta de Castilla y León; 20Io. Premio CONAMA a la sostenibilidad. Ministerio de Agricultura; 2013. Premio Macario Asenjo Ponce al desarrollo rural. Fundación Macario Asenjo.

El funcionamiento del Museo no obedece a reglas muy precisas. Téngase en cuenta que se trata de una iniciativa privada, de una Asociación Cultural, de una pequeña población, que tiene en el voluntariado su apoyo fundamental. Es el tiempo libre de los socios el que marca el ritmo de los trabajos. En consecuencia, el museo no tiene un horario de atención al público previamente establecido, se abre cuando los visitantes lo demandan. No obstante, existe un régimen de visitas guiadas que se conciertan telefónicamente. Las que se realizan en grupo son las que, principalmente, se acogen a esta modalidad.

En relación con los aspectos económicos, se ha de apuntar que, si bien es la junta directiva de la Asociación la que elabora y aprueba el presupuesto general, en el que también están incluidos los ingresos y gastos de los Museos, su comisión de coordinación tiene suficiente autonomía para gestionar los fondos generados directamente por estos. Aportaciones voluntarias de los visitantes; subvenciones y ayudas que puedan obtenerse de la administración y de la empresa privada, y premios que puedan ganarse son sus fuentes de financiación. No existe, por tanto, un presupuesto fijo. Cuando se dispone de fondos suficientes, se acometen las reformas que se precisen o se emprenden las actuaciones que se requieran; mientras tanto, la Asociación se hace cargo de los gastos corrientes de funcionamiento.

1o Estas muestras de aceptación se toman como indicadores de la contribución social de la iniciativa y, a veces, no muchas, como el mejor tratamiento para los momentos de desánimo. 


\section{Perspectivas de futuro}

Por lo que se refiere a las ideas y proyectos de futuro, hemos de manifestar que el objetivo fundamental es el de seguir realizando las actividades y prestando los servicios que se han expuesto con anterioridad, poniendo especial atención en aquellos aspectos que se han identificado como puntos de mejora. No obstante, su realización a corto o medio plazo dependerá de la disponibilidad presupuestaria existente.

Se ha de elaborar un manual de procedimiento del Museo para organizar y planificar todos los aspectos relacionados con él, utilizando siempre los mismos criterios establecidos.

Se ha de seguir con los trabajos de inventario y catalogación de los fondos del Museo y la puesta a disposición de los investigadores y del público, en general, las bases de datos correspondientes. Se precisará para ello encontrar la financiación necesaria a través de subvenciones o convenios con otras instituciones (becas, prácticas profesionales, etc.).

Se ha de intensificar, igualmente, la presencia en Internet y la utilización de las nuevas tecnologías. Para ello se está trabajando en la construcción de una página web específica para los Museos de Otones. Se continuará con la tarea de elaboración de códigos QR y se potenciará la comunicación y la información en las redes sociales.

Otro de los campos que requieren mayor esfuerzo es el de la investigación. Se han de impulsar proyectos desde la propia Asociación (participación en jornadas, congresos y demás iniciativas de este orden, elaboración de guías didácticas destinadas al público infantojuvenil, elaboración de documentos divulgativos, entre otros). Asimismo se ha de facilitar la llegada de investigadores externos dando a conocer los recursos disponibles.

También se continuará en la pretensión de seguir ofreciendo exposiciones temáticas de carácter temporal. Los recursos didácticos para la enseñanza de la geografía y Los materiales de la diversidad serán dos de las muestras a organizar en un futuro próximo. El servicio de préstamo de los fondos del Museo, en general, y de las exposiciones monográficas, en particular, seguirá estando a disposición de las instituciones que lo soliciten.

En el campo de las relaciones institucionales se seguirá reforzando las ya establecidas en los ámbitos territoriales más cercanos (Diputación provincial, Ayuntamientos, Gal Segovia-Sur, Centros Educativos de Educación Infantil y Primaria, Institutos, Facultades de Educación y Centros de Formación del Profesorado) y se procurará emprender otras que aseguren la presencia del Museo de Otones en los foros y redes de referencia, como la Sociedad Española para el Estudio del $\mathrm{Pa}$ trimonio Histórico-Educativo (SEPHE). Esta medida supondría un reconocimiento definitivo de la iniciativa y facilitaría la participación en sus actividades científicas y societarias.

Finalmente, será preciso continuar acometiendo obras de ampliación, remodelación y acondicionamiento del edificio que alberga el Museo. Una mejor conservación, distribución y exposición de sus fondos conforme a criterios historiográficos y museísticos más precisos, así como la facilitación de otras actividades como las de consulta, investigación, almacenaje, etc., así lo requieren. Algunos de los proyectos que se han avanzado dependen de que estas actuaciones se lleven a cabo. 
EL MUSEO PEDAGÓGICO DE OTONES. UNA EXPERIENCIA RURAL

EN LA DIFUSIÓN DEL PATRIMONIO EDUCATIVO

JUAN FRANCISCO CEREZO MANRIQUE Y MIGUEL ÁNGEL CEREZO MANRIQUE

La inminente aprobación de un nuevo programa para el desarrollo rural, basado en la metodología LEADER ${ }^{\text {II }}$, mantiene vivas las esperanzas de encontrar financiación.

\section{Para concluir}

Llegados a este punto final, hemos de manifestar que somos conscientes de las limitaciones que presenta el Museo Pedagógico de Otones; de que, tal vez, no reúne todas las exigencias que un manual de procedimiento exigiría o de que no cumple todas las funciones que un Museo tiene asignadas. A pesar de todo ello, y más allá de la modesta contribución que esta iniciativa pueda suponer a la recuperación y difusión del patrimonio educativo, merece la pena conservarla y mejorarla porque se ha convertido en un lugar de encuentro donde afloran las mejores emociones y valores, en el que se suscita el diálogo y se opera una transformación, esperemos que no solo momentánea, en la que la utopía educativa pareciera tener lugar (Hernández Díaz, 1997; Álvarez Domínguez, 20I2). Estos sentimientos los expresan muchos de los visitantes del Museo que, sin disimular su escepticismo inicial y su sorpresa ante lo que contemplan, manifiestan su agradecimiento por el trabajo realizado. El libro de visitas del Museo está repleto de estos testimonios.

Por otra parte, los Museos de Otones y, particularmente, el Pedagógico, se han convertido en un elemento dinamizador fundamental, desde la cultura y la educación, de esta pequeña población.

\section{Bibliografía}

AA. vv. (2008) Museos Pedagógicos. La memoria recuperada. Huesca: Departamento de Educación, Cultura y Deporte/Museo Pedagógico de Aragón.

Álvarez Domínguez, P. (2007) La museología de la educación como nuevo campo de investigación para la Historia de la Educación. Hacia la construcción del Museo Pedagógico Andaluz. En F. Sánchez Pascua (coord.) Relaciones Internacionales en la Historia de la Educación. Junta de Ampliación de Estudios e Investigaciones cientificas (1907-2007) (pp. 409-423). Cáceres: SEDHE y Universidad de Extremadura.

Álvarez Domínguez, P. (dir.) (2009) Pedagogía Museística: didáctica virtualidad y difusión del patrimonio histórico-educativo. Sevilla: Universidad de Sevilla. A3D Edición Digital.

Álvarez Domínguez, P. (20io) Nuevo concepto de los museos de educación. En J. Ruiz BeRRIO El patrimonio histórico-educativo. Su conservación y estudio (pp. 139-167). Madrid: Biblioteca Nueva.

Álvarez Domínguez, P. (20II) La recuperación del patrimonio histórico-educativo. Museos de Pedagogía, Enseñanza y Educación y Posibilidades Didácticas. CABÁs: Patrimonio Histórico-Educativo, 5, I-20.

Álvarez Domínguez, P. (20I2) Educar en emociones y transmitir valores éticos: un desafío para los Museos de Pedagogía. Educació i História: Revista d'História de l'Educació, 22, 93-116.

ANELE (1992) El libro y la escuela. Libro conmemorativo de la exposición. Biblioteca Nacional. Madrid. 1992. Madrid: Asociación Nacional de Editores de Libros y Material de Enseñanza.

" Es preciso destacar la importancia decisiva que los programas de desarrollo rural, implementados con fondos europeos y nacionales, y utilizando la metodología LEADER, de gestión participativa y descentralizada, han tenido para los proyectos socioculturales de las pequeñas poblaciones, como el que aquí se refiere. 
Cabornero, J. (coord.) (1997) Recuerdos de un olvido. Los libros en que aprendimos. Valladolid: Junta de Castilla y León. Catálogo de exposición.

Carrillo, I. y Collelldemont, E. (2007) Construir un museo pedagógico virtual. Fundamentos teóricos y elementos de gestión. En A. Escolano (ed.) La cultura material de la escuela. En el centenario de la Junta para la Ampliación de Estudios 1907-2007 (pp. 355-369). Berlanga de Duero: CEINCE.

CARrillo, I. y otros (20II) Los museos pedagógicos y la proyección cívica del patrimonio educativo. Gijón: Trea Ediciones.

Castro, E. (20I4) Mupega: io años de proyectos y realidades. En A. Badanelli, M. Poveda y C. Rodríguez (coords.) Pedagogía Museística. Prácticas, usos didácticos e investigación del patrimonio educativo (pp. 219-225). Madrid: Universidad Complutense. Facultad de Educación.

Cebrián, M. (coord.) (1993) La escuela del ayer. Valladolid: stes. Catálogo de exposición.

Cerezo, J. F. y Cerezo, M. Á. (20oI) La última escuela de Otones de Benjumea. Segovia: Asociación para el desarrollo rural de Segovia Sur.

Dávila, P. y Naya L. M. a (20I4) Proceso de construcción y avances realizados en el Museo de la Educación de la Universidad del País Vasco. En A. Badanelli, M. Poveda y C. RodríGUez (coords.) Pedagogía Museística. Prácticas, usos didácticos e investigación del patrimonio educativo. Madrid: Universidad Complutense. Facultad de Educación.

Depaepe, M. y Simon, F. (20I4) Sobre el futuro del pasado de la Educación: Museos de la enseñanza y su relación con la Historia de la Educación. En A. Badanelli, M. Poveda y C. Rodríguez (coords.) Pedagogía Museística. Prácticas, usos didácticos e investigación del patrimonio educativo (pp. 35-43). Madrid: Universidad Complutense. Facultad de Educación.

Escolano, A. (dir.) (1997) Historia ilustrada del libro escolar en España. Del Antiguo Régimen a la Segunda República. Madrid: Fundación Germán Sánchez Ruipérez.

Escolano, A. (dir.) (1998) Historia ilustrada del libro escolar en España. De la posguerra a la reforma educativa. Madrid: Fundación Germán Sánchez Ruipérez.

Escolano, A. (2000) Las culturas escolares del siglo xx. Encuentros y desencuentros. Revista de Educación, número extraordinario, 20I-20I8.

Escolano, A. (2002) Memoria de la educación y cultura de la escuela. En A. Escolano y J. M. Hernández Díaz (coords.) La memoria y el deseo. Cultura de la escuela y educación deseada (pp. 19-42). Valencia: Tirant lo Blanch.

Escolano, A. (dir.) (2006) Historia ilustrada de la escuela en España. Madrid: Fundación Germán Sánchez Ruipérez.

Escolano, A. (2007) El Centro Internacional de la Cultura Escolar como Centro de Memoria. En A. Escolano (ed.) La cultura material de la escuela. En el centenario de la Junta para la ampliación de Estudios 1907-2007 (pp. 233-242). Berlanga de Duero: CEINCE.

Escolano, A. (ed.) (2007) La cultura material de la escuela. En el centenario de la Junta para la Ampliación de Estudios 1907-2007. Berlanga de Duero: CEINCE.

Escolano, A. y Hernández Díaz, J. M. (1990) Cien años de escuela en España (1875-1975). Salamanca: Diputación Provincial. Catálogo de exposición.

Escolano, A. y Hernández Díaz, J. M. (coords.) (2002) La memoria y el deseo. Cultura de la escuela y educación deseada. Valencia: Tirant lo Blanch.

Fernández, M. (2003) Los museos: espacios de cultura, espacios de aprendizaje. Iber. Didáctica de las Ciencias Sociales, Geografía e Historia, 36, 55-61.

Fundación Santillana (1988) La escuela del ayer en Cantabria. Madrid: Taurus. Catálogo de exposición.

Gómez GARcía, M. ${ }^{a}$ N. (2006) El aula escolar, escenario, narración y metáfora: nuevas fuentes para la Historia de la Educación. Historia de la Educación. Revista Interuniversitaria, $34 \mathrm{I}-358$. 
EL MUSEO PEDAGÓGICO DE OTONES. UNA EXPERIENCIA RURAL

EN LA DIFUSIÓN DEL PATRIMONIO EDUCATIVO

JUAN FRANCISCO CEREZO MANRIQUE Y MIGUEL ÁNGEL CEREZO MANRIQUE

GonzÁlez Ruiz, J. (2007) El Centro de Recursos, Interpretación y Estudios de la Escuela de Cantabria. En A. Escolano (ed.) La cultura material de la escuela. En el centenario de la Junta para la Ampliación de Estudios 1907-2007 (pp. 219-222). Berlanga de Duero: CEINCE.

Hernández Díaz, J. M. (1993) Las exposiciones pedagógicas y la historia material de la educación. En AA. vv. Educación y europeísmo: de Vives a Comenio (pp. 321-332). Málaga: SEDHE, Universidad de Málaga.

Hernández Díaz, J. M. (1997) La etnografía escolar entre el corazón y la razón. Vela Mayor. Revista de Anaya Educación, II, 43-5I.

Hernández Díaz, J. M. (200o) Los museos de la educación en España. En R. Fernándes y M. Louro Felgueiras (orgs.) A Escola Primaria: entre a imagen e a memoria (pp. 94-I04). Porto: Projecto Museu Vivo da Escola Primária.

Hernández Díaz, J. M. (2002) Etnografía e historia material de la escuela. En A. Escolano y J. M. Hernández Díaz (coords.) La memoria y el deseo. Cultura de la escuela y educación deseada (pp. 225-246). Valencia: Tirant lo Blanch.

Hernández Díaz, J. M. (2003) Museos Pedagógicos y Exposiciones Educativas en España en los inicios del siglo xxi. En V. Peña (coord.) I Foro Ibérico de Museísmo Pedagóxico. O museísmo pedagóxico en España e Portugal: itinerarios, experiencias e perspectivas. Actas. Santiago de Compostela: mupega, Consellería de Educación e Ordenación Universitaria da Xunta de Galicia.

Jiménez, R. (2003) El proyecto de Museo Pedagógico de Aragón. En V. PeÑa (coord.) I Foro Ibérico de Museísmo Pedagóxico. O museísmo pedagóxico en España e Portugal: itinerarios, experiencias e perspectivas. Actas. Santiago de Compostela: Mupega, Consellería de Educación e Ordenación Universitaria da Xunta de Galicia.

Juan, V. (2007) El Museo Pedagógico de Aragón. Virutas de un proyecto. En A. Escolano (ed.) La cultura material de la escuela. En el centenario de la Junta para la Ampliación de Estudios 1907-2007 (pp. 2II-2I8). Berlanga de Duero: CEINCE.

Juan, V. (ed.) (2008) Museos Pedagógicos. La memoria recuperada. Huesca: Gobierno de Aragón. Departamento de Educación, Cultura y Deporte. Museo Pedagógico de Aragón.

López Martín, R. (200I) La escuela por dentro. Perspectivas de la cultura escolar en la España del siglo $X X$. Valencia: Universitat de València.

Martín, B. (2007) El museo pedagógico de la Universidad de Salamanca. Foro de Educación, 9, 349-358.

Martín, B. y Ramos, I. (2008) Museo pedagógico de la Universidad de Salamanca. Una apuesta abierta de educación hacia el futuro. En I Encontro Iberoamericano de Museos Pedagóxicos e Museólogos da Educación (pp. 517-530). Santiago de Compostela: Mupega-Xunta de Galicia.

mupega (2003) I Foro Ibérico de Museísmo Pedagóxico. Santiago: Museo Pedagóxico de Galicia.

Ossenbach, G. (20Io) Manuales escolares y patrimonio histórico-educativo. Educatio Siglo $X X I, 2$, IIS-I32.

Ossenbach, G.; Somoza, M. y Badanelli, A. (2007) La Base Virtual Patre-Manes de textos escolares europeos y latinoamericanos: análisis de una experiencia. En A. Escolano (ed.) La cultura material de la escuela. En el centenario de la Junta para la Ampliación de Estudios 1907-2007 (pp. 337-354). Berlanga de Duero: CEINCE.

Pastor, M. ${ }^{a}$ I. (2004) Pedagogía museística: nuevas perspectivas y tendencias actuales. Barcelona: Ariel.

Peña, V. (dir.) (200I) Museo Pedagóxico de Galicia. Manual de identidade corporativa. Santiago de Compostela: Conselleria de Educación e Ordenación Universitaria. Secretaria Xeral. Mupega.

PeÑA, V. (coord.) (2003) I Foro Ibérico de Museísmo Pedagóxico. O museísmo pedagóxico en España e Portugal: itinerarios, experiencias e perspectivas. Actas. Santiago de Compostela: mupega, Consellería de Educación e Ordenación Universitaria da Xunta de Galicia. 
Peña, V. (2003) O Museo Pedagóxico de Galicia (MUPega): antecedentes, actualidade e previsións de futuro. En I Foro Ibérico de Museísmo Pedagóxico. O museísmo pedagóxico en España e Portugal: itinerarios, experiencias e perspectivas. Actas. Santiago de Compostela: Mupega, Consellería de Educación e Ordenación Universitaria da Xunta de Galicia.

Peña, V. (2006) Museo Pedagógico de Galicia (mupega). Boletín Informativo de la Sociedad Española para el Estudio del Patrimonio Histórico-Educativo, I.

Peralta, J. (2009) Museo del Niño, 1987-2009. Participación Educativa, I2, I82-193.

Revista de Ciencias de la Educación (2012). Monográfico sobre Pensar y sentir la escuela: I jornadas de patrimonio histórico educativo, 23I-232.

REyes, M. (2OI2) El patrimonio histórico escolar como recurso formativo: el Museo Pedagógico de la Universidad de Huelva. Revista de Ciencias de la Educación, 231-232, 375-388.

Rubio Mayoral, J. L. (2009) Museos pedagógicos y experiencias educativas. Apuntes de futuro. Cuadernos de Historia de la Educación, 6, 93-IIo.

Ruiz Berrio, J. (ed.) (2000) La cultura escolar en Europa. Madrid: Biblioteca Nueva.

Ruiz Berrio, J. (2000) Hacia una tipología de los Museos de Educación. En El libro y la educación (pp. 58-75). Madrid: ANELE.

Ruiz Berrio, J. (2002) Pasado, presente y porvenir de los museos de educación. En A. Escolano y J. M. Hernández DíAz (coords.) (2002) La memoria y el deseo. Cultura de la escuela y educación deseada (pp. 43-65). Valencia: Tirant lo Blanch.

Ruiz Berrio, J. (2006) Historia y Museología de la Educación. Despegue y reconversión de los museos pedagógicos. Historia de la Educación. Revista Interuniversitaria, 25, 27I-290. Salamanca: Universidad de Salamanca.

Ruiz Berrio, J. (20Io) El patrimonio histórico-educativo. Su estudio y conservación. Madrid: Biblioteca Nueva.

SANCHIDRIÁN, C. (20I4) El patrimonio histórico-educativo como base de una metodología reflexiva en la enseñanza de la Historia de la Educación. En A. Badanelli, M. Poveda y C. Rodríguez (coords.) Pedagogía Museística. Prácticas, usos didácticos e investigación del patrimonio educativo (pp. 34I-348). Madrid: Universidad Complutense. Facultad de Educación.

Somoza, M. y Yanes, C. (2009) La (re)construcción de los procesos educativos en la museología escolar. Reflexiones en torno a sus relaciones. En R. BERruezo y S. Conejero (coords.) El largo camino hacia una educación inclusiva: la educación especial y social del siglo XIX a nuestros días (pp. 647-657). Pamplona-Iruñea: SEDHE, Universidad Pública de Navarra.

Terrón, A. (2003) El proceso de creación del Museo Escolar Selgas: un análisis crítico. En V. PEÑa (coord.) I Foro Ibérico de Museísmo Pedagóxico. O museísmo pedagóxico en España e Portugal: itinerarios, experiencias e perspectivas. Actas. Santiago de Compostela: Mupega, Consellería de Educación e Ordenación Universitaria da Xunta de Galicia.

ViÑaO, A. (2002) Relatos y relaciones autobiográficas de profesores y maestros. En A. EscoLANo y J. M. Hernández Díaz (coords.) La memoria y el deseo. Cultura de la escuela y educación deseada (pp. I42-180). Valencia: Tirant lo Blanch.

ViñaO, A. (2005) La memoria escolar: restos y huellas, recuerdos y olvidos. En Homenaje al Profesor Alfonso Capitán (pp. 739-758). Murcia: Servicio de Publicaciones de la Universidad de Murcia. 